\title{
ASSESSMENT OF SEISMIC SUSCEPTIBILITY OF RC BUILDINGS
}

\author{
C Ravi Kumar Reddy ${ }^{1}$, P.Ch.Sanjeeva Rao $^{2}$, J Usha Kranti ${ }^{3}$, ChSrivalli Lakshmi ${ }^{4}$ \\ ${ }^{1}$ Professor, Civil Engineering Department, $K$ L University, Vijayawada AP, India \\ ${ }^{2}$ Professor, Civil Engineering Department, RVR\&JCCE, Guntur, AP, India \\ ${ }^{3}$ Asst. Professor, Civil Engineering Department, RVR\&JCCE, Guntur, AP, India \\ ${ }^{4}$ PG Scholar, Civil Engineering Department, RVR\&JCCE, Guntur, AP, India
}

\begin{abstract}
Earthquake is one of the most destructive calamities. Many earthquakes in numerous parts of world including India have caused loss of human lives and even damaged many properties causing collapse of structures. Even though one cannot prevent earthquake, the loss caused due to it can be curtailed by adopting appropriate measures. The measures adopted should reduce damage to the structures and hence life and other losses can be decreased. Earthquake risk assessment is necessary for disaster mitigation, disaster management and emergency preparedness. Vulnerability assessment is one of the major parts of the hazard risk assessment. Seismic vulnerability of building signifies how much a structure is susceptible to the damage caused by a particular magnitude of earthquake force. The vulnerability functions acts as input parameter for loss estimation for specific buildings or building class. Here in this paper the detailed procedure to evaluate the seismic performance of reinforced concrete buildings has been studied. There are three important methods to determine the seismic inelastic displacement namely Capacity Spectrum Method, Displacement Coefficient Method and Pushover Analysis; with the help of these methods the performance and capacity of a building can be evaluated. For non linear analysis of buildings using tools, the detailed knowledge of non linear modelling is must. The non linear modelling includes development of moment-rotation relationship and thus moment-curvature curves are needed. Nonlinear modelling of frame elements and shear walls are explained in detail. Vulnerability curves or fragility curves are the one which shows the probability of failure of the given building for a given displacement under a given damage state.
\end{abstract}

$* * *$

\section{INTRODUCTION}

Relative movement of the tectonic plates leads to shaking of earth's crust causing earthquake. The magnitude of earth shaking varies from very low where humans cannot recognise the shaking to very high where ground gets separated. Depending on the capacity of structure and magnitude of earthquake, the earthquake may lead to serious damage of the structure. The damage to structure results in economic loss, functionary loss, injuries and even loss of lives. Hence mitigation of risk associated hazard is required to reduce the loss caused by the earthquake. In general, any risk/disaster management process is associated with hazard/threat assessment, asset value assessment, vulnerability assessment, risk assessment, cost and benefit analysis and assessment of mitigation techniques. Vulnerability assessment plays vital role in process of risk/disaster management. Broadly vulnerability assessment consist of identifying site and building systems design issues, evaluation of design issue against type and level of hazard and determination of level of protection required for each mitigation measure against each threat.

To construct a loss model to an earthquake for a city, region or country involves compiling databases of earthquake activity, ground conditions, ground-motion prediction equations, building stock and infrastructure exposure, and vulnerability characteristics of the exposed inventory. The main aim of a loss model is to calculate the seismic hazard at all the sites of interest and to relate this hazard with the vulnerability of the exposed building stock such that the damage distribution of the building stock can be predicted; damage ratios, which relate the cost of repair and replacement to the cost of demolition and replacement of the structures, can then be used to calculate the loss. Vulnerability of building is important in causing risk to life. The seismic vulnerability of a structure can be described as its susceptibility to damage by ground shaking of a given intensity. The aim of a vulnerability assessment is to obtain the probability of a given level of damage to a given building type due to a scenario earthquake.

The level of damage is directly associated with deaths, injuries, economic losses. Damage functions are to be developed to assess the damage level for given level of earthquake. The outcome of vulnerability assessment can be used in loss estimation. Loss estimation is essential in disaster mitigation, emergency preparedness. Here the work is concentrated towards studying the details of analytical seismic vulnerability assessment of RC buildings and thus developing the analytical vulnerability curves for same.

Here the paper concentrates on performing nonlinear static analysis and thus evaluates the performance of RC buildings under seismic forces. According to Sermin et al, 2005, "pushover analysis is an approximate analysis method in which the structure is subjected to monotonically increasing lateral forces with an invariant height-wise distribution until a target displacement is reached." Lang et al, 2002 studied seismic vulnerability of existing buildings in Switzerland. 
He developed analytical capacity curves for masonry and reinforced buildings. Damage grades were defined on capacity curves. Calvi et al., 2006 has discussed the development of vulnerability assessment methods in 30 years.

\section{MODELLING OF REINFORCED CONCRETE BUILDING}

The material behaviour of concrete and reinforcement are specified as given IS456. The strength of the concrete in the structure is taken as 0.67 times the $f c k$ (characteristic strength of the concrete). The reinforcement strength is taken as strength at the yield point. The beams were modelled with given material and cross sectional properties as line elements. The beam and columns are modelled as line elements along the centre line of members but in reality the beams end at the face of column and beams will be either at centre line or side line of the column. So the beams are offset at the face of column and cardinal points are used to shift the beams from centre line of column. Beams and slabs are top centred to have monolithic slab action along with beams. The Shear wall is modelled as a equivalent frame element attached to the rigid links at the end.

For carrying out the non-linear analysis for a given structure the knowledge of behaviour of the materials used in the building under nonlinear condition is essential. Hence modelling of beams and columns and incorporating the effect of material nonlinearities becomes a very important step of nonlinear procedures. The only, but important, difference to linear static model is that the column and beam elements in this model are modelled to fail. This is done by having the hinges in all the possible places of hinge formations. Beams and columns are assumed to fail by plastic hinge formation at either ends. In the model, columns and beams are modelled as line elements with hinges provided at their ends, whose stiffness changes depending on the moment experienced by the beam or column during course time of analysis.

The hinge properties for beam or column are obtained from the Moment-rotation curve which is specific to the element and the axial load on it. In a large building, elements with similar dimensions and loads can be grouped together and hence same properties for hinge can be used in order to minimize the effort. The modelling of buildings has been done in SAP 2000.

A) Procedure to develop Moment-Curvature Relation Theoretical determination of moment-curvature characteristics for reinforced concrete section with flexure and axial load is based on the following assumptions.

1. Plane sections before bending remains plane after bending.

2. Stress-strain relationship for both concrete and steel is known.

3. Tension carrying capacity of concrete is ignored.

The curvatures associated with a range of bending moments and axial loads may be determined using these assumptions and from strain compatibility and equilibrium of forces. Programs are developed in Matlab 7.10 is used to get moment-curvature relationship of beams and columns.

B) Analysis of Reinforced Concrete Building

Performance of the selected RC building has been evaluated under different seismic condition. The calculation of the performance point has been done manually and same is compared and validated with SAP2000 calculation. Static nonlinear pushover analysis is carried out on three selected RC building models. First model is a two dimensional RC four storey frame, the second model is a three dimensional seven storey RC buildings structure and last model is similar to second model but has shear wall in its middle frame.

\section{RESULTS AND DISCUSSIONS}

A) Static Nonlinear analysis of two dimensional frame A four story 2-D building frame of same paper is considered for validation the obtained pushover curve. The frame has story height of $2800 \mathrm{~mm}$ each and bay width of $4000 \mathrm{~mm}$. The all beams have cross sectional dimension $500 \times 200 \mathrm{~mm}$ and column S1/S2 has cross sectional dimension of $500 \times 250 \mathrm{~mm}$ and $\mathrm{S} 3 / \mathrm{S} 4$ has cross sectional dimension of $400 \times 250 \mathrm{~mm}$. Static nonlinear analysis (pushover analysis) was carried out on the 2-D frame using SAP2000. The pushover curve obtained from SAP2000 adopting default hinge is as shown in the figure 1 .

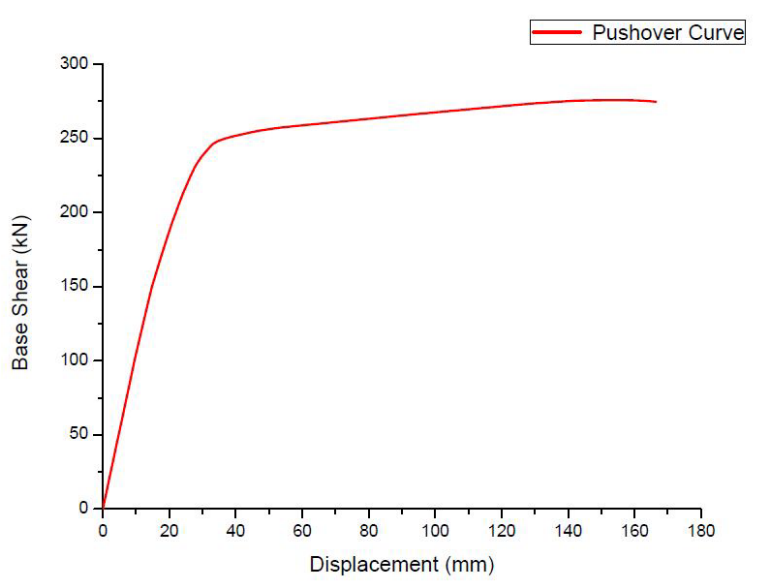

Figure 1: Pushover Curve obtained from SAP2000 analysis by adopting default hinge

B) Seismic Performance Evaluation of three dimensional frame without shear wall

The method uses inelastic response spectrum and static nonlinear analysis. Two variants of the same structures one with shear wall (model-1) and another without shear wall (model-2) was considered in the study. In design the strongcolumn and weak-beam concept for both model-1 and model- 2 were used. To validate the pushover procedure both model with and without shear wall are considered here. Modal analysis is carried out in SAP2000. The Pushover analysis of seven storey building is carried out by using SAP2000 v15. The lateral load distribution for pushover analysis is adopted as per literature and the weak-beam and strong-column design concept has been used. The modeling 
assumes the lumped/concentrated plastic zone and hence here plastic hinges are provided at the end of the frame elements The analysis is carried out by adopting SAP2000 default nonlinear properties. The results of pushover analysis are shown in figure 2.

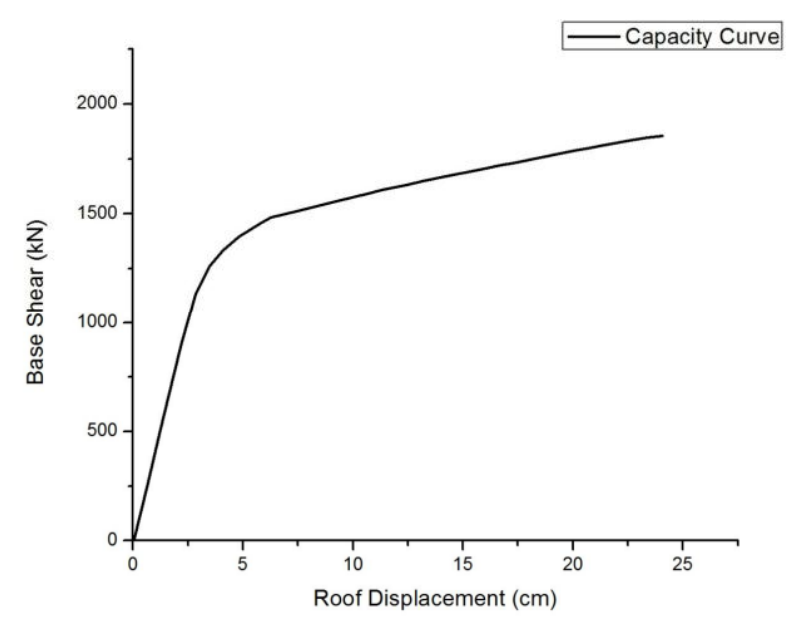

Figure 2: Capacity (Pushover) Curve obtained from SAP2000 analysis by adopting default hinge

C) Seismic Performance Evaluation of 3-D RC frame without Shear Wall

SAP2000 v15 has the capability of evaluating performance point using capacity spectrum method and same has been used for evaluating the performance point of the considered building. Figure 3 shows the result obtained.

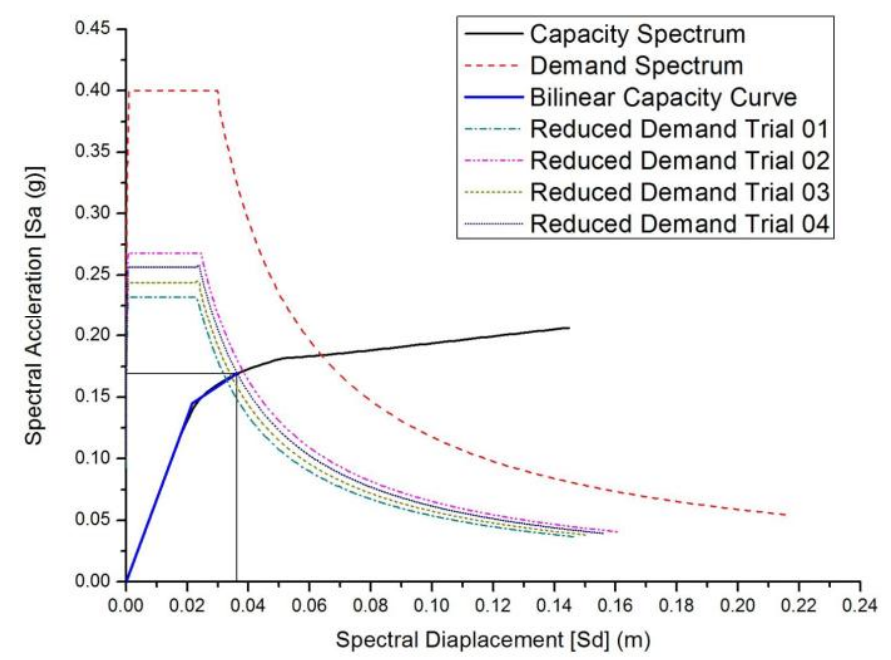

Figure 3: Evaluation of Performance Point Manually Using CSM of RC Building in Soil Type 2 Under Zone 3, MCE

D) Seismic Performance Evaluation of three dimensional frame with shear wall

The Pushover analysis of seven storey building is carried out by using SAP2000 v15. The lateral load distribution for pushover analysis is adopted as per literature and the weakbeam and strong-column design concept has been used. The modelling assumes the lumped/concentrated plastic zone and hence here plastic hinges are provided at the end of the frame elements. The analysis is carried out by adopting
SAP2000 default nonlinear properties. The results of pushover analysis are shown in figure 4.

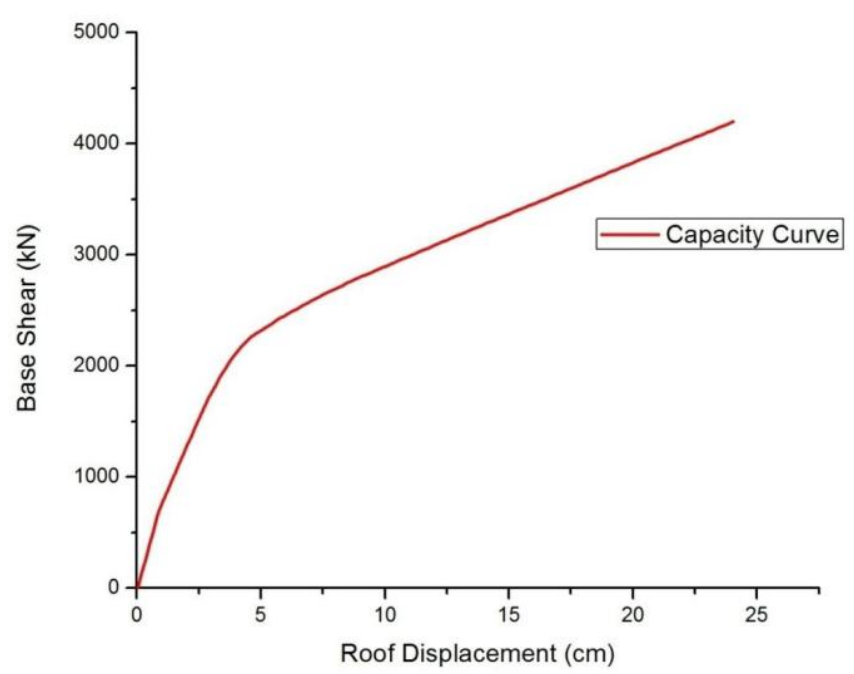

Figure 4: Capacity (Pushover) Curve of 7 Storey Building

With Shear Wall obtained from SAP2000 analysis by adopting default hinge

\section{CONCLUSIONS}

1. The static nonlinear pushover analysis is efficient and effective way of assessing the engineering properties of not much complicated building, but it does has certain limitations too.

2. Capacity spectrum method is one of the effective way of finding out the inelastic displacement, which uses the intersection of capacity spectrum and reduced demand spectrum to estimate performance point. In other hand modification factors are used by displacement coefficient.

3. Capacity spectrum method is iterative process to estimate inelastic displacement and displacement coefficient method is direct method of estimating target displacement.

4. Since capacity spectrum method is a semi graphical method, it gives more appropriate results regarding the response of buildings under earthquake ground motion, and it also gives brief idea about the impact of retrofitting on building response. Displacement coefficient method is fast method to estimate target displacement.

5. To perform nonlinear analysis, nonlinearity must be incorporated in the elements in terms of concentrated hinges, whose behaviour must satisfy the appropriate building code.

6. Performance based evaluation of structures gives appropriate behaviour at elemental as well as global level.

7. Since the considered example building has area of shear walls more than area of column, most of the lateral loads are resisted by shear walls and hence performance of building is in immediate occupancy level under all soil condition.

8. Study of some of the important vulnerability methods clearly shows that there is no unique or best solution for assessing vulnerability of selected building stock User should adopt the appropriate method depending on the importance of the project. 
9. Discrete damage state probabilities developed for RC type building stock under different soil and seismic condition, which can be used in loss estimation and risk estimation.

\section{REFERENCES}

1. Sermin O., (2005). "Evaluation of Pushover Procedures for Frame Structures", PhD Thesis, Middle East Technical University

2. Lang K., (2002) "Seismic vulnerability of existing buildings." Doctoral thesis, Institute of Structural Engineering, Swiss Federal Institute of Technology, Zurich. 3. Calvi G.M., Pinho R., Magenes G., Bommer J.J., Restrepo-Vélez L.F. and Crowley H.,(2006). "Development of Seismic Vulnerability Assessment Methodologies over the Past 30 years", ISET Journal of Earthquake Technology, Vol 43, 75-104. 